\title{
Normal Pressure Hydrocephalus Secondary to Intracranial Mass: A Case Series
}

\author{
Abdul Basit Ansari ${ }^{1}$, Noman Lateef ${ }^{1}$, Abubakar Tauseef ${ }^{1}$, Aneela Darbar $^{2 *}$ \\ ${ }^{1}$ Dow Medical College, Dow University of Health Sciences, Karachi, Pakistan \\ ${ }^{2}$ Neurosurgery Department, Division of surgery, Aga Khan University Hospital, Karachi, Sindh, Pakistan
}

*Corresponding author: Dr. Aneela Darbar, Assistant Professor of Neurosurgery Department at Aga Khan University Hospital, Karachi, Sindh, Stadium Road, P.O Box 3500, Karachi 74800, Pakistan, Tel: +92 324 4000000; E-mail: aneela.darbar@aku.edu

\begin{abstract}
Background: Normal pressure hydrocephalus is a rare type of communicating hydrocephalus. The symptoms of NPH consist of a triad of gait disturbances, urinary incontinence, and progressive decline in mental function. The definitive treatment is Ventriculo-peritoneal shunt.

Case Description: We would like to present a case series, consisting of two cases, of patients who were diagnosed with an intracranial tumor with co-existing symptoms of normal pressure hydrocephalus. In both cases, the CSF protein content was raised and patient's symptoms improved after placement of ventriculo-peritoneal shunt.

Conclusion: We believed that increased protein content in CSF in some patients with CNS tumors, might cause NPH by impairing CSF reabsorption at the level of the arachnoid granulations. The association of NPH secondary to CNS tumor and increased CSF protein content should be further evaluated.
\end{abstract}

Keywords: Gait disturbance; Hydrocephalus; Normal pressure hydrocephalus; Sphenoid wing meningioma; Urinary incontinence; Vestibular schwannoma

\section{Received Date: September 06, 2017 \\ Accepted Date: October 13, 2017 \\ Published Date: October 20, 2017}

Citation: Darbar, A., et al. Normal Pressure Hydrocephalus Secondary to Intracranial Mass: A Case Series. (2017) Int J Neurol Brain Dis 4(2): 1- 4.

DOI: $10.15436 / 2377-1348.17 .1668$

\section{Case Report}

\section{Background}

Normal pressure hydrocephalus is a rare type of communicating hydrocephalus first described by Hakim et al, in 1965 usually affecting patients over 65 years $^{[1,2]}$. The symptoms of NPH consist of a triad of gait disturbances, urinary incontinence, and progressive decline in mental function ${ }^{[3,4]}$. Ventriculomegaly is essential for this disease and can be demonstrated by Computed Tomography or Magnetic Resonance Imaging. The diagnosis of NPH is confirmed by the removal of a relatively large volume of CSF $(50-60 \mathrm{ml})$, after which patients often exhibits prompt improvement ${ }^{[5]}$. The definitive treatment is Ventriculo-peritoneal shunt ${ }^{[6]}$.

\section{Clinical Presentation \\ CASE 1}

A 76 years old man presented with complaints of rightsided visual loss, confusion, amnesia, and on and off visual hallucinations for 3 weeks. There was also history of frequent urination, constipation, poor appetite, and sleep disturbance. The biochemical and hematological parameters were insignificant. There was an increase in CSF protein of $114 \mathrm{mg} / \mathrm{dl}$. Contrast CT of the brain showed enhancing broad-based extra-axial lesion adjacent to right greater sphenoid wing slightly compressing optic chiasm with hyper-vascularity and hyperostosis of bone representing a Meningioma. Axial T1 and T2 weighted MRI showed an extra-axial mass, overlying right greater sphenoid wing (figure 1). He underwent right pterional craniotomy for the total excision of the lesion. Biopsy examination revealed WHO Grade 1 Meningioma. Post-operative MRI showed re-demonstration of heterogeneous area with calcifications in the right temporal lobe representing residual lesion (figure 2) and re-demonstration of mass lesion with calcification in the left frontal lobe. Thereafter he was discharged and regularly followed up, but he did not show much of an improvement. 


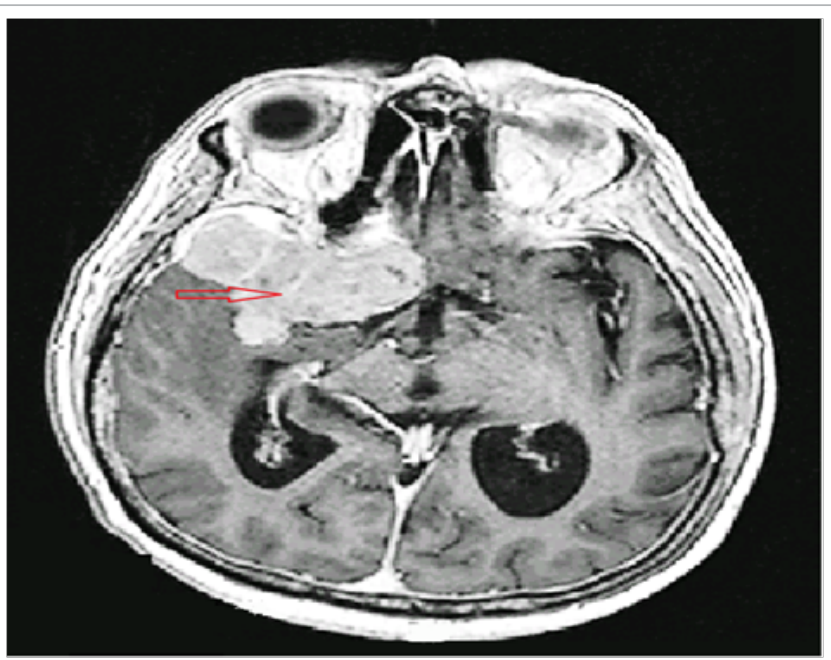

Figure 1: Preoperative T1 weighted post contrast MRI (axial view) showing an extra axial lesion overlying right greater wing of sphenoid with homogenous enhancement and mild to moderate ventricular dilatation.

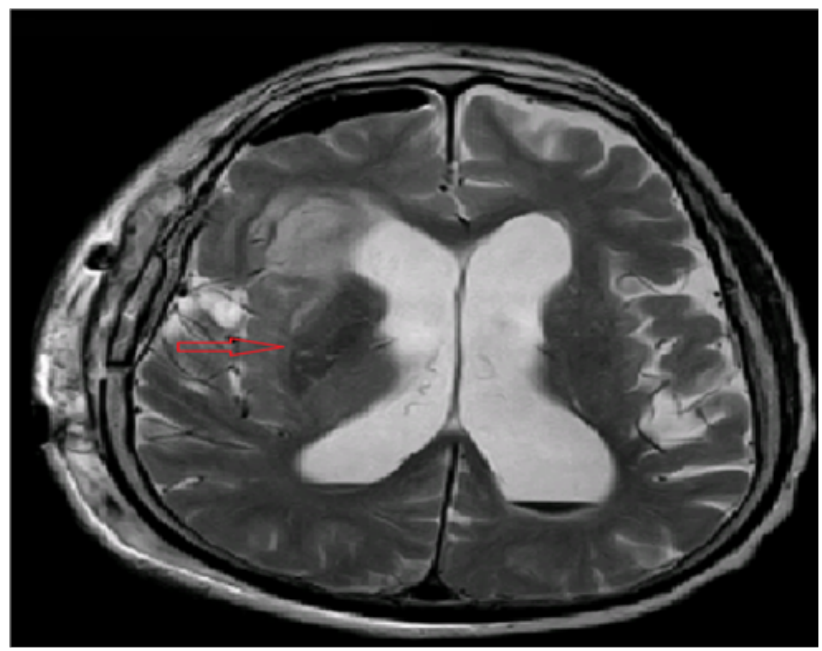

Figure 2: Postoperative T2 weighted MRI (axial view) showing a postsurgical changes of hemorrhagic cavity and edema in the right fronttemporal lobe and minimal intraventricular blood with no residual tumor lesions and moderate to severe ventricular dilatation.

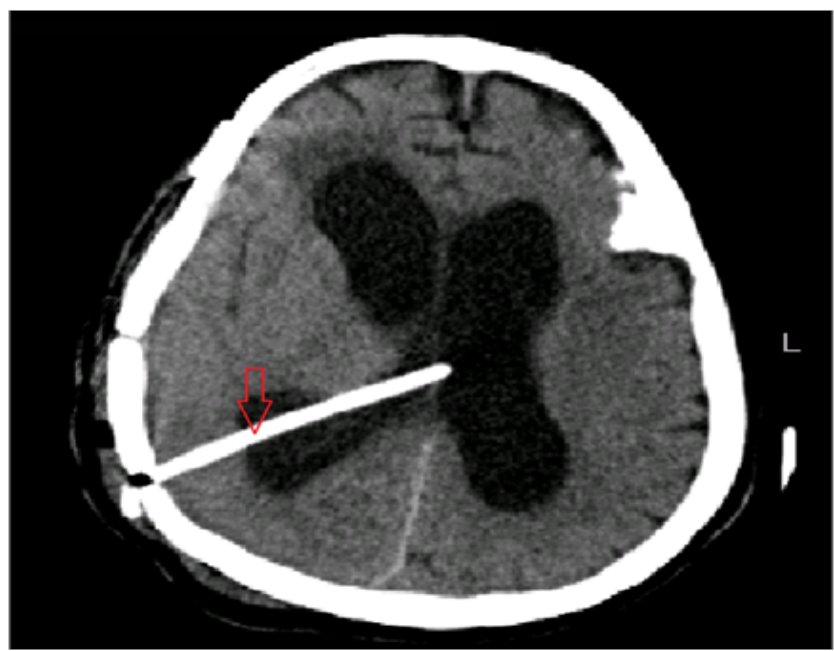

Figure 3: Postoperative CT scan of the patient (axial view) showing placement of VP shunt in the right occipital horn of the lateral ventricle and moderate ventricular dilation.
After few weeks, on one of his follow-up visits, he presented with gait disturbance and urinary incontinence. Neurologic examination revealed classic features of a normal pressure hydrocephalus. A Lumbar puncture was performed but his symptoms did not show much improvement and he was subsequently planned for Lumbar drain placement. He improved and was scheduled for a ventriculo-peritoneal shunt. A postoperative CT scan of the brain showed mild decrease in size of ventricles with shunt placement (figure 3). For a period of one year with multiple follow-ups and valve re-adjustment, patient displayed improvement in gait and cognition.

\section{CASE 2}

A 69 years old woman presented with complaints of recurrent falls, almost twice weekly for last 6 months, urinary incontinence, left sided weakness and hallucinations for 3 months. There was an associated diagnosis of left sided sensori-neural hearing loss 8 years back. Neurological examination revealed patient awake but disoriented to time, place, and person, hearing loss and magnetic gait. Rest of the neurological examination was unremarkable. The biochemical and hematological parameters were insignificant. CSF DR showed protein of $169 \mathrm{mg} / \mathrm{dl}$. MRI showed generalized brain atrophy, dilated lateral ventricles and right sided cerebello-pontine angle mass, most likely suggestive of Vestibular schwannoma with no compression on brain stem (figure 4).
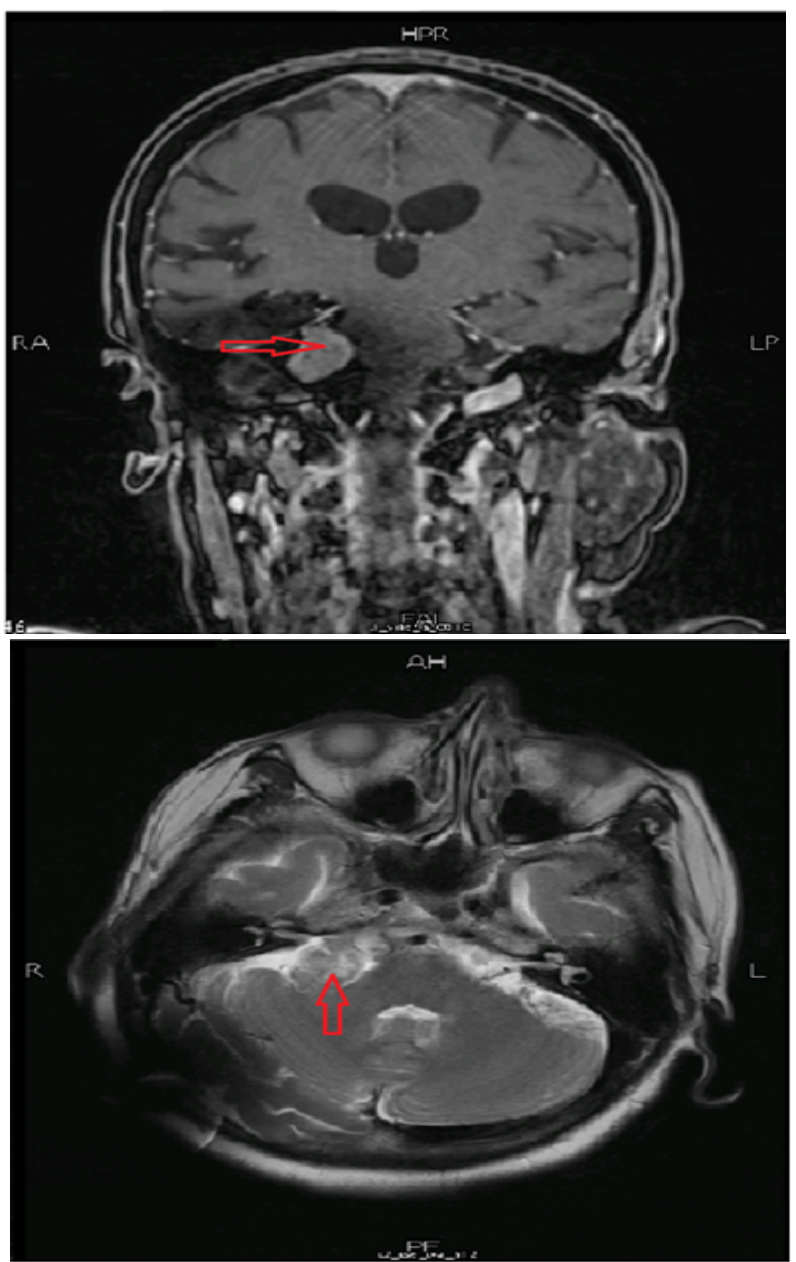

Figure 4: Postoperative MRI scan of the patient (coronal and axial view) showing well defined rounded lesion in right cerebellopontine angle. 
Based on clinical presentation and MRI findings, presumptive diagnosis of normal pressure hydrocephalus secondary to $\mathrm{CP}$ angle mass was made. She undergone lumbar puncture and lumbar drain placement that showed improvement in her symptoms and confirmed her diagnosis. Thereafter, she was scheduled for ventriculo-peritoneal shunt surgery. Postoperatively, patient was well orientated with gait improvement and urinary incontinence same. Post-operative, CT scan showed a mild decrease in size of ventricles with shunt placement (figure 5). She was regularly followed up, with careful valve settings adjustments, during which progressive improvement in symptoms was seen. She was then referred to get cyber knife radiosurgery for her small left sided cerebellopontine angle schwannoma.

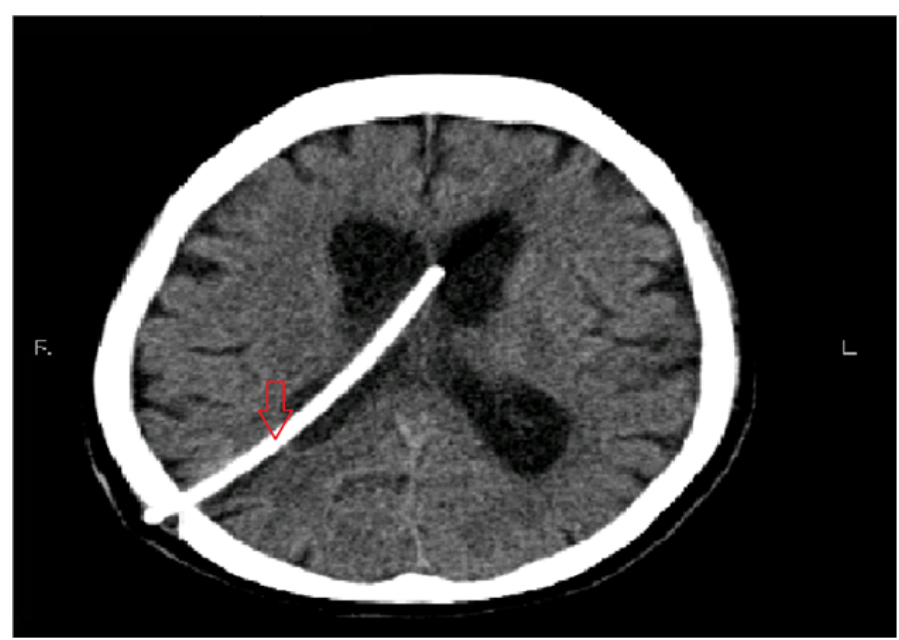

Figure 5: Postoperative CT scan of the patient (axial view) showing placement of VP shunt in the body of the left lateral ventricle and ventricular dilation.

\section{Discussion}

Normal pressure hydrocephalus (NPH) can be either idiopathic or secondary to complications to head injury, subarachnoid hemorrhage, meningitis, CNS tumor ${ }^{[7]}$. The sign and symptoms of NPH are similar to other more common neurological disorders of geriatric group, leading to motor problems and dementia, such as Parkinson's and Alzheimer's disease. The aim is to correctly diagnose the disease and calculate the risks and benefits of placing ventriculo-peritoneal shunt, as there is a high risk of complications in ventriculo-peritoneal shunt surgery.

The symptoms of sphenoid wing meningioma are related to mass effects on the adjacent structures. In first case, our patient had mixed symptoms suggestive of tumor, accompanied by decreased mentation, altered behavior, gait disturbance, and urinary incontinence. However, presence of radiologic evidence leads us to the diagnosis of meningioma. Persistence of symptoms postoperatively along with age, history, and clinical exam, ventriculomegaly and improvement after lumber drain placement supported the diagnosis of NPH.

The second case had a vestibular schwannoma, a benign primary intracranial tumor of nerve sheath cells of cranial nerve eight. It usually presented with hearing loss, tinnitus, loss of balance, vertigo. In this case, the patient had mixed symptoms of NPH and vestibular schwannoma. Only after lumbar puncture followed by lumbar drain placement, our patients shows improvement is his symptoms. Finally, a ventriculo-peritoneal shunt was placed that resulted in gradual improvement in his symptoms. According to a study, vestibular schwannoma is also associated with non-obstructive hydrocephalus and in all these patients, hyperproteinorrachia i.e.; increased protein content in $\mathrm{CSF}$ is seen ${ }^{[8]}$. We believed that increased protein content in CSF in some patients with CNS tumors, might cause NPH by impairing CSF reabsorption at the level of the arachnoid granulation ${ }^{[8]}$. This mechanism can be possibly applicable to our cases as the lumbar puncture revealed high amount of protein, though not confirm that our patient develop NPH after the tumor or it coexists with tumor from the beginning.

A few cases have been reported, in which intracranial pathologies coexist with normal pressure hydrocephalus, or a normal pressure hydrocephalus develops after their treatment. Out of which three cases are worthwhile to discuss here. First case was of a 57 year-old woman presented with symptoms of NPH later diagnosed as convexity meningioma and second case was of a 68 year-old male with history of involuntary arm movements and symptoms of NPH, later diagnosed as $\mathrm{GBM}^{[9]}$. In another case, symptoms of NPH developed after radio surgery for meningioma ${ }^{[10]}$. The cases stated above presented either with mixed symptoms of intracranial tumor as well as NPH or with development of symptoms after treatment.

Our study is unique from other studies by the fact that ours showed a relationship of intracranial mass presenting with the signs and symptoms of NPH as shown in other studies, but in both of our cases the protein levels in the CSF were elevated, not seen in other studies. Also this is the first reported such study in the region, hence it is further suggested that more research be conducted on this condition, so that one has a wider perspective of the clinical scenario.

\section{Conclusion}

The association of NPH secondary to CNS tumor and CSF protein content should be further evaluated. Also, secondary NPH may also be more common than idiopathic NPH for similar reasons in these patients. Studies involving formation of non-obstructive hydrocephalous in patients after development of CNS tumor is recommended.

\section{Conflict of interest}

This statement is to certify that all Authors have seen and approved the manuscript being submitted. We warrant that the article is the Authors' original work. We warrant that the article has not received prior publication and is not under consideration for publication elsewhere. On behalf of all Co-Authors, the corresponding Author shall bear full responsibility for the submission.

This research has not been submitted for publication nor has it been published in whole or in part elsewhere. We attest to the fact that all Authors listed on the title page have contributed significantly to the work, have read the manuscript, attest to the validity and legitimacy of the data and its interpretation, and agree to its submission to the "Journal".

No additional authors will be added post submission, unless editors receive agreement from all authors and detailed information is supplied as to why the author list should be amended. 


\section{References}

1. Hakim, S., Adams, R.D. The special clinical problem of symptomatic hydrocephalus with normal cerebrospinal fluid pressure: Observations on cerebrospinal fluid hydrodynamics. (1965) J Neurol Sci 2(4): 307327.

PubMed | CrossRef | Others

2. Adams, R.D., Fisher, C.M., Hakim, S., et al. Symptomatic OccultHydrocephalus with Normal Cerebrospinal-Fluid Pressure - A Treatable Syndrome. (1965) N Engl J Med 273: 117-126.

PubMed | CrossRef | Others

3. Iddon, J.L., Pickard, J.D., Cross, J.J., et al. Specific patterns of cognitive impairment in patients with idiopathic normal pressure hydrocephalus and Alzheimer's disease: a pilot study. (1999) J Neurol Neurosurg Psychiatry 67(6): 723-732.

PubMed |CrossRef|Others

4. Koenigsberg, R.A., Faro, S.H., Hershey, B.L., et al. Neuroimaging. In: Goetz CG, 2nd edn. Textbook of clinical neurology. (2003) Philadelphia: Elsevier 427-470.

PubMed |CrossRef | Others

5. Wikkelsö, C., Andersson, H., Blomstrand, C., et al. Normal pressure hydrocephalus. Predictive value of the cerebrospinal fluid tap-test. (1986) Acta Neurologica Scandinavica 73(6): 566-573.

PubMed | CrossRef|Others

6. Marmarou, A., Young, H.F., Aygok, G.A., et al. Diagnosis and management of idiopathic normal-pressure hydrocephalus: a prospective study in 151 patients. (2005) J Neurosurg 102(6): 987-997.

PubMed | CrossRef | Others

7. Tisell, M., Hellström, P., Ahl-Börjesson, G., et al. Long-term outcome in 109 adult patients operated on for hydrocephalus. (2006) Br J Neurosurg 20(4): 214-221.

PubMed | CrossRef| Others

8. Bloch, J., Vernet, O., Aubé, M., et al. Non-obstructive hydrocephalus associated with intracranial schwannomas: hyperproteinorrhachia as an etiopathological factor? (2003) Acta Neurochir (Wien) 145(1): 73-78. PubMed | CrossRef | Others

9. Naydenov, E., Bussarsky, V., Minkin, K., et al. Normal Pressure Hydrocephalus as an Unusual Presentation of Supratentorial Extraventricular Space-Occupying Processes: Report on Two Cases. (2012) Case

Rep Oncol 5(1): 143-147.

PubMed | CrossRef | Others

10. Kajiwara, M., Yamashita, K., Ueba, T., et al. Normal pressure hydrocephalus after radiosurgery for sphenoid ridge meningioma. (2009) J Clin Neurosci 16(1): 162-164.

PubMed|CrossRef|Others

Online ISSN: 2377-1348

Journal Title: International Journal Neurology and Brain Disorders Journal Short Name: Int J Neurol Brain Disord
Ommega Online Publishers

E-mail: neurology@ommegaonline.com

Website: www.ommegaonline.org 